\title{
Rapid Geriatric Assessment in Primary Care Practice
}

\author{
Reshma A. Merchant ${ }^{1}$, J.E. Morley ${ }^{2}$

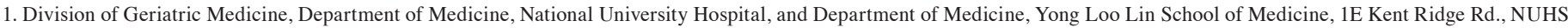

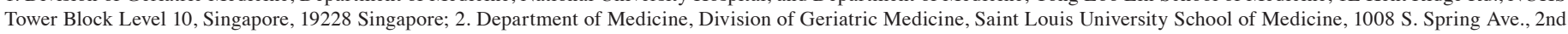
Floor, St. Louis, Missouri 63110 USA

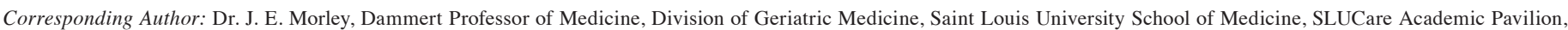
Section 2500, 1008 S. Spring Ave., 2nd Floor, St. Louis, MO 63110 USA, Email: john.morley@health.slu.edu

\section{Trends and innovations in primary care geriatric assessments}

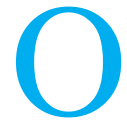

riginally, geriatric assessment focused on older persons with functional impairment and demonstrated that aggressive therapy could improve quality of life and function and decrease hospitalization, nursing home placement and mortality (1). Recently a number of new geriatric syndromes, e.g., frailty, sarcopenia, anorexia of aging/weight loss and cognitive impairment have been identified as syndromes, which when identified and treated early, can prevent the development of functional impairment (2). Primary care is often the foundation of healthcare system in many countries, has major impact on population health, and is a core site for preventive health screening (3). Because of the limited time available in primary care practice, a number of screening tests have been developed to allow the recognition of the presence of these syndromes (4).

Frailty can be defined as a condition which, when the person is exposed to a stressful event, they fail to compensate and prone to adverse outcomes such as falls, functional decline, institutionalization and mortality. Fried et al (5) developed a set of screening tests (unintentional weight loss, exhaustion, low grip strength, slow walking speed, low physical activity) that defined older persons who were physically frail. Rockwood et al (6) defined frailty as deficit accumulation or the percentage of co-morbidities an individual might have. At Saint Louis University we developed the FRAIL, which consists of 5 questions identifying if the person has fatigue, problems performing resistance or aerobic activity, how many illnesses they have and if they had lost weight (7). Persons with fatigue can be further investigated for depression, use of anticholinergic drugs, sleep apnea, anaemia and hypothyroidism. Persons with resistance or aerobic activity problems require exercise therapy. Persons with 5 or more illnesses should be screened for inappropriate pharmacotherapy and those with weight loss should be screened with the "MEALS-ON-WHEELS" mnemonic (Figure 1) for the treatable causes of weight loss (8). The FRAIL predicts poor outcomes to a similar extent as the Fried et al (5) questionnaire and the Rockwood frailty screens (9). Becoming frail marks a major downhill slide in older persons and if identified early before the onset of disability, frailty is potentially reversible $(10,11)$.
Figure 1. "MEALS-ON-WHEELS" mnemonic for the treatable causes of weight loss

MEALS-ON-WHEELS mnemonic

M Medications

E Emotional (Depression)

A Alcoholism; elder Abuse

L Late life paranoia

S Swallowing problems

$\begin{array}{ll}\text { O } & \text { Oral problems } \\ \text { N } & \text { Nosocomial infections }\end{array}$

N Nosocomial infections

W Wandering and other dementia related problems

H Hyperthyroidism

E Enteral problems

E Eating problems

L Low salt, low fat diet

S Stones (gallstones)

Sarcopenia is defined as a loss of function due to a loss of lean muscle mass (12). SARC-F has 5 questions and screens for sarcopenia (13). It is recommended by the European Working Group on Sarcopenia to be used to screen for sarcopenia (14). Treatment requires leucine enriched essential amino acids and referral to physical therapy followed by long term exercise therapy (15). If the person is having falls, they should also be investigated for syncope and orthostatic hypotension.

The Simplified Nutritional Appetite Questionnaire (SNAQ) identifies persons with anorexia of aging (16). Persons with a positive SNAQ are at high likelihood of losing weight in the next 6 months. Treatment is to provide high caloric nutritional supplements and to treat any reversible causes of weight loss as previously described. The SNAQ has been useful in allowing early identification of treatable causes of weight loss. 
Cognitive dysfunction is very common, particularly in the old-old. Classically it was screened for by the Mini Mental State Examination (MMSE), which has recently been copyrighted (17). Alternative cognitive screeners include the Montreal Cognitive Assessment (MOCA) (18) and the St. Louis University Metal Status (SLUMS) examination (19). The MiniCog is a short rapid screening test for dementia (20). The Rapid Cognitive Screen (RCS) is a slightly longer test that can screen for Mild Cognitive Impairment (MCI), as well as dementia (21). The AD-8 is a simple screening dementia which is best answered by a family member (22) and the myMemCheck ${ }^{\circledR}$ is a rapid self-assessment test to identify MCI or dementia (23). The MMSE, MOCA and SLUMS take 8 to 12 minutes to do, making the shorter screens more realistic for primary care practice. It is important that older persons identify the treatments that they would prefer in emergencies or might prefer after they develop cognitive impairment (24). This is also an ideal time to identify "what matters" to them as outlined in the John A. Hartford 4Ms approach to aging (25).

To provide a simple geriatric assessment that can be incorporated in the Medicare Annual Wellness visit in the USA (26) or in yearly visits done in other countries, at Saint Louis University we developed the Rapid Geriatric Assessment (RGA) (27). (https://www.slu.edu/medicine/internal-medicine/ geriatric-medicine/aging-successfully/pdfs/rga_form_4-6-17. pdf ). The RGA can be completed in under 5 minutes. We have used this in over 10,000 older persons in the United States (28) and over 2,000 older persons in Singapore (29). In Singapore, the RGA has been developed into a computerized assessment and available in the app store. At Saint Louis University we have developed a computerized version of the Annual Wellness Visit that includes the RGA. We believe that RGA should be conducted annually for persons over 65 years of age in all primary care practices. Persons identified as being frail or sarcopenic should be advised by the family practitioner to become involved in an exercise group $(30,31)$.

The RGA has been demonstrated to lead to improved cognition and increased function when used to refer older persons in a rural primary care practice to appropriate exercise and Cognitive Stimulation Therapy (32). "HAPPY" program is another example where frailty screening was done for community dwelling older adults using the FRAIL scale, and twice-weekly dual-task exercise reduced prevalence of frailty in $75 \%$ of older adults (33). Screening and appropriate therapy in primary care requires the development of an interprofessional team. As time availability is the greatest deterrent to screening in primary care, the RGA which takes less than 5 minutes to complete, can be done by the "rooming person" with management pathway is an ideal screening test for geriatric syndromes. When a person is identified as having a geriatric syndrome and if an appropriate interprofessional support service is not available, the primary care provider should consider referring to a geriatrician or a neurologist.

Future research requires the comparison of outcomes in primary care practices utilizing the RGA and having the interprofessional support services in place to regular primary care practices who are not doing the screening.
Conflicts of Interest: The authors declare there are no conflicts of interest regarding this commentary.

\section{References}

1. Rubenstein, L. Z. Evolving models of comprehensive geriatric assessment. J Am Med Dir Assoc, 2015;16(6), 446-447, doi:10.1016/j.jamda.2015.03.012.

2. Morley, J. E. Frailty and Sarcopenia: The New Geriatric Giants. Rev Invest Clin, 2016;68(2), 59-67.

3. Starfield, B., Shi, L., \& Macinko, J. Contribution of primary care to health systems and health. The Milbank quarterly, 2005;83(3), 457-502, doi:10.1111/j.14680009.2005.00409.x.

4. Fougere, B., Cesari, M., Arai, H., Woo, J., Merchant, R. A., Flicker, L., et al. Editorial: Involving Primary Care Health Professionals in Geriatric Assessment. J Nutr Health Aging, 2018;22(5), 566-568, doi:10.1007/s12603-018-1001-0.

5. Fried, L. P., Tangen, C. M., Walston, J., Newman, A. B., Hirsch, C., Gottdiener, J., et al. Frailty in older adults: evidence for a phenotype. J Gerontol A Biol Sci Med Sci, 2001;56(3), M146-156, doi:10.1093/gerona/56.3.m146.

6. Rockwood, K., \& Mitnitski, A. Frailty in relation to the accumulation of deficits. J Gerontol A Biol Sci Med Sci, 2007;62(7), 722-727, doi:10.1093/gerona/62.7.722.

7. Morley, J. E., Little, M. O., \& Berg-Weger, M. Rapid Geriatric Assessment: A Tool for Primary Care Physicians. J Am Med Dir Assoc, 2017;18(3), 195-199, doi:10.1016/j. jamda.2016.11.017.

8. Morley, J. E. Rapid Geriatric Assessment: Secondary Prevention to Stop AgeAssociated Disability. Clin Geriatr Med, 2017;33(3), 431-440, doi:10.1016/j. cger.2017.03.006.

9. Malmstrom, T. K., Miller, D. K., \& Morley, J. E. A comparison of four frailty models. J Am Geriatr Soc, 2014;62(4), 721-726, doi:10.1111/jgs.12735.

10. Escourrou, E., Herault, M., Gdoura, S., Stillmunkés, A., Oustric, S., \& Chicoulaa, B Becoming frail: a major turning point in patients' life course. Fam Pract, 2019;36(2), 231-236, doi:10.1093/fampra/cmy043.

11. Dent, E., Morley, J. E., Cruz-Jentoft, A. J., Woodhouse, L., Rodriguez-Manas, L., Fried, L. P., et al. Physical Frailty: ICFSR International Clinical Practice Guidelines for Identification and Management. J Nutr Health Aging, 2019;23(9), 771-787, doi:10.1007/s12603-019-1273-z.

12. Fielding, R. A., Vellas, B., Evans, W. J., Bhasin, S., Morley, J. E., Newman, A. B., et al. Sarcopenia: an undiagnosed condition in older adults. Current consensus definition: prevalence, etiology, and consequences. International working group on sarcopenia. Journal of the American Medical Directors Association, 2011;12(4), 249256, doi:10.1016/j.jamda.2011.01.003.

13. Woo, J., Leung, J., \& Morley, J. E. Validating the SARC-F: a suitable community screening tool for sarcopenia? J Am Med Dir Assoc, 2014;15(9), 630-634, doi:10.1016/j.jamda.2014.04.021.

14. Cruz-Jentoft, A. J., Bahat, G., Bauer, J., Boirie, Y., Bruyère, O., Cederholm, T., et al. Sarcopenia: revised European consensus on definition and diagnosis. Age and Ageing, 2018;48(1), 16-31, doi:10.1093/ageing/afy169.

15. Bauer, J., Morley, J. E., Schols, A., Ferrucci, L., Cruz-Jentoft, A. J., Dent, E., et al. Sarcopenia: A Time for Action. An SCWD Position Paper. J Cachexia Sarcopenia Muscle, 2019;10(5), 956-961, doi:10.1002/jcsm.12483.

16. Wilson, M. M., Thomas, D. R., Rubenstein, L. Z., Chibnall, J. T., Anderson, S., Baxi, A., et al. Appetite assessment: simple appetite questionnaire predicts weight loss in community-dwelling adults and nursing home residents. Am J Clin Nutr, 2005;82(5), 1074-1081, doi:10.1093/ajen/82.5.1074.

17. Folstein, M. F., Folstein, S. E., \& McHugh, P. R. "Mini-mental state". A practical method for grading the cognitive state of patients for the clinician. J Psychiatr Res, 1975;12(3), 189-198, doi:10.1016/0022-3956(75)90026-6.

18. Ciesielska, N., Sokołowski, R., Mazur, E., Podhorecka, M., Polak-Szabela, A., \& Kędziora-Kornatowska, K. Is the Montreal Cognitive Assessment (MoCA) test better suited than the Mini-Mental State Examination (MMSE) in mild cognitive impairment (MCI) detection among people aged over 60? Meta-analysis. Psychiatr Pol, 2016;50(5), 1039-1052, doi:10.12740/pp/45368.

19. Tariq, S. H., Tumosa, N., Chibnall, J. T., Perry, M. H., 3rd, \& Morley, J. E. Comparison of the Saint Louis University mental status examination and the minimental state examination for detecting dementia and mild neurocognitive disorder-a pilot study. Am J Geriatr Psychiatry, 2006;14(11), 900-910, doi:10.1097/01. Jgp.0000221510.33817.86.

20. Borson, S., Scanlan, J., Brush, M., Vitaliano, P., \& Dokmak, A. The mini-cog: a cognitive 'vital signs' measure for dementia screening in multi-lingual elderly. Int J Geriatr Psychiatry, 2000;15(11), 1021-1027, doi:10.1002/10991166(200011)15:11<1021::aid-gps234>3.0.co;2-6.

21. Malmstrom, T. K., Voss, V. B., Cruz-Oliver, D. M., Cummings-Vaughn, L. A., Tumosa, N., Grossberg, G. T., et al. The Rapid Cognitive Screen (RCS): A Point-ofCare Screening for Dementia and Mild Cognitive Impairment. J Nutr Health Aging, 2015;19(7), 741-744, doi:10.1007/s12603-015-0564-2.

22. Galvin, J. E., Roe, C. M., Xiong, C., \& Morris, J. C. Validity and reliability of the AD8 informant interview in dementia. Neurology, 2006;67(11), 1942-1948, doi:10.1212/01. wnl.0000247042.15547.eb. 
23. Mansbach, W. E., Mace, R. A., Tanner, M. A., \& Simmons, S. P. A path to early diagnosis of mild cognitive impairment and dementia: validity and reliability of the myMemCheck ${ }^{\circledR}$ self-administered screening tool. Fam Pract, 2020;37(4), 561-567, doi:10.1093/fampra/cmaa014.

24. Abele, P., \& Morley, J. E. Advance Directives: The Key to a Good Death? J Am Med Dir Assoc, 2016;17(4), 279-283, doi:10.1016/j.jamda.2016.01.020.

25. Mate, K. S., Berman, A., Laderman, M., Kabcenell, A., \& Fulmer, T. Creating AgeFriendly Health Systems - A vision for better care of older adults. Healthc (Amst), 2018;6(1), 4-6, doi:10.1016/j.hjdsi.2017.05.005.

26. Little, M. O., Sanford, A. M., Malmstrom, T. K., Traber, C., \& Morley, J. E. Incorporation of Medicare Annual Wellness Visits into the Routine Clinical Care of Nursing Home Residents. J Am Geriatr Soc, 2021;69(4), 1100-1102, doi:10.1111/ jgs.16984.

27. Morley, J. E., \& Adams, E. V. Rapid Geriatric Assessment. J Am Med Dir Assoc, 2015;16(10), 808-812, doi:10.1016/j.jamda.2015.08.004.

28. Sanford, A. M., Morley, J. E., Berg-Weger, M., Lundy, J., Little, M. O., Leonard, K., et al. High prevalence of geriatric syndromes in older adults. PLoS One, 2020;15(6), e0233857, doi:10.1371/journal.pone.0233857.
29. Merchant, R. A., Hui, R. J. Y., Kwek, S. C., Sundram, M., Tay, A., Jayasundram, J., et al. Rapid Geriatric Assessment Using Mobile App in Primary Care: Prevalence of Geriatric Syndromes and Review of Its Feasibility. Front Med (Lausanne), 2020;7, 261, doi:10.3389/fmed.2020.00261.

30. Jadczak, A. D., Dollard, J., Mahajan, N., \& Visvanathan, R. The perspectives of prefrail and frail older people on being advised about exercise: a qualitative study. Fam Pract, 2018;35(3), 330-335, doi:10.1093/fampra/cmx108.

31. Merchant, R. A., Morley, J. E., \& Izquierdo, M. Exercise, Aging and Frailty: Guidelines for Increasing Function. The journal of nutrition, health \& aging, 2021; doi:10.1007/s12603-021-1590-x.

32. Lundy, J., Hayden, D., Pyland, S., Berg-Weger, M., Malmstrom, T. K., \& Morley, J. E. An Age-Friendly Health System. J Am Geriatr Soc, 2021;69(3), 806-812, doi:10.1111/ jgs.16959.

33. Merchant, R. A., Tsoi, C. T., Tan, W. M., Lau, W., Sandrasageran, S., \& Arai, H. Community-Based Peer-Led Intervention for Healthy Ageing and Evaluation of the 'HAPPY' Program. The journal of nutrition, health \& aging, 2021;doi:10.1007/ s12603-021-1606-6.

How to cite this article: Reshma A. Merchant, J.E. Morley. Rapid Geriatric Assessment in Primary Care Practice. J Nutr Health Aging. 2021;25(9):1034-1036, http://dx.doi. org/10.1007/s12603-021-1681-8 